\title{
GOBERNANZA DE LA MEMORIA EN LA CIUDAD: ANÁLISIS CRÍTICO DE EDIFICACIONES COLONIALES Y POST COLONIALES COMO PATRIMONIO CULTURAL URBANO
}

GOVERNANCE OF MEMORY IN THE CITY: CRITICAL ANALYSIS OF COLONIAL AND POSTCOLONIAL EDIFICES AS URBAN CULTURAL HERITAGE

María Esperanza Rock ORCID 0000-0002-0910-5269

\section{Andrés Torres González}

ORCID 0000-0001-8768-5919

Universidad de San Sebastián Concepción, Chile

\section{Resumen}

Los procesos de patrimonializacion ponen en valor elementos significativos del pasado de un pueblo, no obstante, su significado muchas veces es subyugado por el crecimiento urbano de las ciudades y sus prácticas de desarrollo las que muchas veces se convierten en políticas de olvido. Este articulo presenta casos de cómo los aparatos gubernamentales que dictaminan las declaratorias de Monumento Histórico son utilizados como banderas de lucha por la identidad local convirtiéndose en soluciones viables y activistas para la detención de mega proyectos de desarrollo en zonas urbanas. Para ello se revisan casos particulares de patrimonialización de dos fuertes coloniales -Nacimiento y Tucapel- con valoración patrimonial pertenecientes a la región del Biobío en Chile, donde estas prácticas de dominio y mercantilización terminan por desdibujar identidades locales y pasan a manos de un discurso en la industria del turismo, descontextualizando y despojando de real sentido de Monumento Histórico. $\mathrm{O}$ que surgen como antagonistas de dicho proceso valorado como patrimonio cultural por su componente de identidad local, activando luchas por la defensa de un pasado común, como en el caso de las ciudades industriales de Lota y Tomé, también emplazadas en la región del Biobío.

Palabras claves: Archivo urbano, patrimonialización, fuerte colonial, Monumentos Nacionales, memoria. 


\section{Resumo}

Os processos de patrimonialização valorizam elementos significativos do passado de um povo, no entanto, seu significado é muitas vezes subjugado pelo crescimento urbano das cidades e suas práticas de desenvolvimento, que muitas vezes se tornam políticas do esquecimento. Este artigo apresenta casos de como o aparato governamental que decide a designação do Monumento Histórico é usado como bandeiras da luta pela identidade local, tornando-se soluçóes viáveis e ativistas para deter mega projetos de desenvolvimento em áreas urbanas. Para isso, são revistos casos particulares de patrimonialização de dois fortes coloniais Nacimiento y Tucapel com avaliação patrimonial pertencentes à região de Biobío no Chile, onde essas práticas de dominação e mercantilização acabam borrando as identidades locais e não passam muito de um discurso na Indústria do turismo, descontextualizando e eliminando o verdadeiro sentido do Monumento Histórico. Ou que surjem como antagonistas desse processo valorizado como patrimônio cultural por seu componente de identidade local, instigando lutas pela defesa de um passado comum, como no caso das cidades industriais de Lota e Tomé, também localizadas na região de Biobío.

Palavras-chave: Arquivo urbano, patrimonialização, forte colonial, Monumentos Nacionais, memória.

\section{Abstract}

Patrimonialization places great value on significant elements of a people's past; however, their meaning is often stifled by rapid urban growth in cities and their development practices, which often become forgotten policies. This article describes some examples of how governmental institutions that dictate the declarations of Historical Monument are used as standard-bearers in the fight for local identity and how they then become viable and activist solutions to halt mega development projects in urban areas. Specifically, we will discuss the patrimonialization of two colonial forts, Nacimiento and Tucapel, both of which have great heritage value and are located the Biobío region in Chile, a country where these practices of domination and commercialization end up blurring local identities and start forming part of the discourse of the tourism industry, thus decontextualizing and stripping the sites of the real sense of Historical Monument. On the other hand, we will see how some sites emerge as antagonists of this process valued as cultural heritage because of their local identity component, inciting a fight for the defense of a common past, as in the case of the industrial cities of Lota and Tomé, also located in the Biobío region.

Keywords: Urban archive, heritage, colonial fort, National Monuments, memory. 
Desde sus orígenes, el patrimonio cultural supone un vínculo directo con la identidad de un grupo humano, que comparte un territorio y una historia común. No obstante, el sentido de la valorización del pasado histórico conjetura una toma de decisiones e intenciones que dictaminan una posteridad que se vincula a situaciones políticas y relaciones de dominio, que quedan en evidencia en inmuebles y espacios edificados en la ciudad. Así, se observa el patrimonio como dominio y jerarquización del pasado y -en la actualidadcomo mercantilización de la memoria histórica, entendiendo la vinculación que ha explotado -sobre todo- la industria del turismo.

Cuando se propone una declaratoria de Monumento Histórico por algún patrimonio cultural, existen aparatos gubernamentales que determinan la memoria-según diversos criterios validados por UNESCO o por políticas internas nacionales como las declaratorias de Monumentos Históricos-, desde la valorización histórica que pasará a convertirse en alguna categoría patrimonial, manteniéndola de manera relativamente "intacta" para la posteridad (Ley No17.288).

A modo de hipótesis se plantea que las declaratorias de monumento histórico, además de posesionar un valor significativo histórico y cultural de un pueblo, en Chile se han convertido en banderas de lucha social por la conservación de las identidades que se han visto vulneradas por el desarrollo y crecimiento de las ciudades.

Para analizarlo, revisaremos algunos casos de patrimonialización de inmuebles urbanos pertenecientes a la región del Biobío en Chile, donde estas prácticas de dominio y mercantilización terminan por desdibujar identidades locales y pasan a manos de un discurso en la industria del turismo, descontextualizando y despojando el real sentido de Monumento Histórico, como en el caso de los fuertes coloniales de Nacimiento y Tucapel; o bien que surgen como antagonistas de dicho proceso valorados como patrimonio cultural, por su componente de identidad local, activando luchas por la defensa de un pasado común, como en el caso de las ciudades industriales de Lota y Tomé.

Desde la historicidad, la etnografía urbana y el análisis como cruces metodológicos, se propone un análisis crítico del concepto de patrimonio en tiempos actuales, donde nos encontramos de cara a los procesos de gobernanza de la memoria y el pasado histórico a través del patrimonio cultural amenazado por el desarrollo, pero también con un mercado extractivista y colonizante que descontextualiza y tergiversa el sentido del pasado en el presente.

¿De qué manera la participación ciudadana puede redefinir la gobernanza de la memoria, desde declaratorias patrimoniales en el marco 
de los procesos de crecimiento urbano en el caso de Lota y Tomé? ¿Cómo lograr conciliar la mirada de desarrollo y progreso con la historia y el pasado local como propuesta de sustentabilidad urbana del patrimonio en el caso de ambas ciudades? Son sólo algunas de las preguntas que se desarrollarán en esta propuesta.

\section{Algo sobre el origen y las ciudades latinas}

El concepto de patrimonio cultural surge con particular fuerza tras la Segunda Guerra Mundial como medida de "restauración" de la historia e identidades culturales de Europa, sobre todo de aquéllas que sufrieron la devastación de la guerra. UNESCO toma un rol fundamental en esto y se comienzan a gestionar mecanismos políticos y gubernamentales en todas las naciones adscritas a esta instancia, para restablecer la vida cotidiana, reconociendo la base histórica del pasado. Esta definición provocó revisar las identidades y tradiciones, donde además se propició la reformulación de la educación.

Bajo este origen, se observa el importante rol que cumple la historia y la memoria al momento de reconstituir sociedades en situaciones posttraumáticas. Volver al pasado supone una solidez en la toma de decisiones, en el contexto de origen de las culturas con un sentido ético y moral que dispone desde cierta autonomía en los procesos más difíciles, bajo una interesante y profunda valoración o autovaloración, siempre y cuando se genere desde procesos participativos y activos.

Este concepto de patrimonio, que se desplegó por todo el mundo, fue adoptando diversas formas hasta provocar lo que se podría homologar a un readymade 1 en las artes de vanguardia. Es decir, se trajeron la idea y los ejemplos de patrimonio importados desde Europa y se procedió a resguardar hitos del pasado que provenían de dicha herencia. No obstante, en Latinoamérica la herencia europea es la colonizadora, lo que provocó que se resguardaran memorias de la colonización en desmedro del patrimonio existente previo a la dominación, elemento que recién hace un par de años comienza a modificarse. El proceso de colonización marcó dinámicas culturales dominadoras que persisten hasta hoy en un álgido momento del neoliberalismo.

Convengamos que la colonización realizada por españoles en territorio americano se compone de diversas estrategias cuyo objetivo se planteó desde

1 El concepto de Ready Made viene del artista dadaísta Marcel Duchamp, quien revitaliza objetos realizados por la industria, los descontextualiza - a algunos los invierte- y finalmente los firma, convirtiéndolos así en obras de arte. En este contexto utilizamos el término "ready made" con el patrimonio cultural, dado que su origen tuvo propósitos claros y concretos en y para Europa. El traslado al continente americano y otros continentes provoca una descontextualización y una resignificación del pasado, así como lo provocan las obras de Duchamp. 
una misión evangelizadora, donde la inclusión de territorios y mano de obra fue justificada para la salvación de los "indígenas bastardos" que habitaban América. Esto de manera burda y resumida, pues lo interesante de este estructural proceso -que creemos hoy persiste desde los nuevos y sofisticados métodos y procesos de conquista vinculados al mercado- es cómo el territorio comienza adoptar ciertos elementos provenientes del "otro", las movilidades internas y las mixturas culturales que provocaron los distintos choques de mentalidades, creencias y cultura en general.

Dado que en Chile no hubo grandes civilizaciones homologables al imperialismo en Europa, como sí se encontraron en Mesoamérica y los Andes Centrales - a modo de ejemplo, los imperios maya, inca, azteca, entre otros-, la milicia española tuvo que reformular su conquista, dado que la estrategia del derrocamiento del gran dignatario no era factible en territorio mapuche.

En ellos, predominaba el acefalismo -al menos como era entendido en el imperialismo-, pues, incluso hasta hoy, se pueden observar agrupaciones en $\mathrm{LOV}^{2}$ o clanes con cierta autonomía. La cultura material era bastante simple en relación a las grandes civilizaciones; sus construcciones eran catalogables como eco-construcciones. En relación a su desarrollo agrícola, podemos decir que tenían un desarrollo a nivel doméstico: la alimentación era complementada con la recolección, la caza y la pesca.

La tierra para los mapuches -como para muchas sociedades- era concebida como un Dios en sí misma o un/os espíritu/s supremo/s que no se podía -ni puede/n- mercantilizar ni sobreexplotar, dado que -del mismo modo que Dios para la iglesia católica- no podía venderse ni dividirse en pedazos, independiente de que con el tiempo se haya ido modificando, dadas las políticas republicanas (CHIHUAILAF, 1999; STEWART y ROCK, 2018). No obstante, la cosmovisión trasciende a lo que luego se instala como procesos de sumisión mercantil, privatización y división de tierras, y todo lo que ello implica.

En consecuencia, podemos decir que en gran parte de la Latinoamérica urbana encontramos "ciudades europeas" construidas sobre las precolombinas o sobre terrenos que extranjeros determinaron como "baldíos" posibles de ser utilizados -conquistados, como el caso del sur de Chile-. En este sentido, volvemos a retomar el término readymade de "ciudades europeas" en contexto latino, decodificando el sentido de la estructura social a través de edificaciones que, en alguna medida, imponen recursos simbólicos culturales y organizacionales -territoriales-a las sociedades donde se insertan, dominando y gobernando el paisaje.

2 Se denomina LOV a un conjunto de familias que reconocen un clan o linaje común. 
En otras palabras, la ciudad se significa como hito de conquista, de soberanía y de empoderamiento territorial, donde la "cultura dominante" se establecía bajo su carácter estético y estilístico, utilizando elementos constructivos posibles de encontrar en cualquier territorio, instalando tecnologías de diversa sofisticación y sentido, y con ello modificando el paisaje de manera dramática.

Por tanto, vamos a observar ahora la colonización en tanto materia y modificación del paisaje. Esto no sólo tiene que ver con el paisaje ecológico, sino con las maneras en que el hombre se instala y ubica en el territorio; la manera que tiene de manipular la tierra y sus frutos, el disciplinamiento del cuerpo (FOUCAULT, 1975) en tanto actividades económicas y militares, y un sinfín de conductas que se deshilan de lo anterior: tipos de cultivos, alimentos, rituales, cosmovisión, mitos, leyendas, tecnologías y todo lo que se reordena y agrupa en torno a distintas culturas. Consiguientemente, hay un paisaje ecológico y cultural que se ve modificado tras la llegada del "otro" (GEERTZ, 1973, 1983; TODOROV, 1982).

En esta lógica, planteamos que la ciudad es también un archivo viviente, un documento posible de ser leído, significado e interpretado, cual si fuese un manuscrito de época, atendiendo además a dinámicas de apropiación conformes a su dinamismo, donde encontramos la real cultura, sincretismos, o bien curiosas y ricas mixturas culturales (ROCK, 2018). La ciudad -en este sentido- es un archivo histórico en sí mismo y constata dinamismos propios de las identidades y la cultura. (ROCK, 2018).

Desde otra arista, observamos que esta llegada del "otro" no es ingenua ni genuina, trae consigo una intencionalidad mercantil solapada a un proyecto ambicioso de misionar con el evangelio. Es así como jesuitas, y posteriormente franciscanos, logran su objetivo con particulares prácticas, incluyendo el exterminio y la esclavitud.

En definitiva, la dominación en la dimensión humana es un fenómeno cuya intención es modificar radical o paulatinamente conductas y creencias del ser humano, lo que involucra de manera directa la identidad, la percepción del mundo y el reconocimiento de nuevos códigos y símbolos, cuyo éxito se manifiesta cuando logra formular o introducirse en la "identidad" del conquistado (ARFUCH, 2002 y HALL, 2000).

\section{Patrimonio, memoria e identidad}

En términos generales, el patrimonio como concepto refiere al valor que tienen las herencias pasadas materiales (muebles o inmuebles) o inmateriales, para un grupo humano que vive en el presente. En este sentido, la mirada siempre se vuelve a la historia desde la propia ausencia del acontecimiento o contemporánea del mismo (DERRIDA, 1971). Así es como el discurso 
histórico (BARTHES, 1984) se pliega en su generalidad al discurso oficial, por tanto dominante, $y$, en su contraste, a la memoria de todos quienes no tienen una participación activa en la toma de decisiones políticas, económicas ni religiosas (FOUCAULT, 1969). Por fortuna de muchos, esto está modificándose y, desde ese cambio, la ciudad aparece como archivo, lo que se percibe como una revelación.

Siguiendo con el análisis anterior, podemos observar que las ciudades en Chile, así como en gran parte de Latinoamérica, fueron fundadas con objetivos de dominación desde la corona española, para demostrar soberanía y, con ello, redefinir el territorio. Sus emplazamientos - por lo general- fueron estratégicos, cercanos a lugares fértiles, con agua, de accesos medianamente fluidos y conectados unos a otros.

Si nos trasladamos a la frontera sur del Chile colonial, las estrategias de dominación y conquista se multiplicaron, dada la importante resistencia a la dominación que dieron los mapuches por defender sus tierras (lucha que persiste hasta hoy). Una de las estrategias recurrentes fue la creación de líneas de ataque con fuertes españoles, donde residían los tercios de soldados, que -algunas veces- venían acompañados de misiones religiosas (GUARDA, 1990). Esto ocurrió desde el siglo XVII hasta comienzos del XVIII, donde en conjunto con el origen de la República, la "Pacificación de la Araucanía" y la "Guerra a Muerte" (TRIVIÑOS, 1994), se sumó, a partir del Siglo XVIII, el fenómeno de la industrialización, surgiendo de manera medianamente simultánea a la formación de la república en la región donde solía estar la frontera sur, región del Biobío con la frontera natural: el río Biobío. Es por esta razón que los casos de estudio a analizar más adelante se ubican geográficamente en dicha área. Por lo tanto, la industrialización desarrollada a mediados del siglo XVIII en el sur de Chile tiene su origen en la minería del carbón, a la que prontamente, dada la tecnología a vapor y los diversos transportes que esta proporcionó, se sumaron también la industria agraria y la textilera. Estos fenómenos provocaron la migración campo-ciudad. Comenzamos a ver dos tipo de ciudades: aquéllas que en sus inicios fueron fundadas por la conquista española y, por otro lado, las que se formaron según los requerimiento industriales, por lo que surgió así el concepto de "Company Town".

La ciudad así se convierte en testigo y manifestación de procesos de dominio, de imbricación cultural contendora de un sinfín de acontecimientos, transacciones comerciales, relacionales, archivos y memorias que la convierten en un importante laboratorio social y viviente. Los estudios culturales, datos simbólicos de apropiación, historia local, movimientos sociales e, incluso, historia de las mentalidades, están ahí, en un momento particular, donde si se saca una "radiografía actual" se observará cómo este "hormiguero humano" 
arroja simultáneamente diversos datos que están operando en las diversas dimensiones, capas constitutivas de una sociedad, cultura e identidades.

El termino de identidad acá no lo vamos a instalar desde el "romanticismo" que sugiere la UNESCO; lo abordaremos desde dimensiones reales y críticas en el sentido en que Hall (1966) y Arfuch (2002) lo analizan. Como sea que este concepto se aborde, siempre apela a un sentir de la cultura, a una "identificación" de alguien hacia un algo, a un ir y venir de información más vinculada al "idealismo" que a la propia realidad (FREUD, 1929). Así es como la identidad se convierte en un sentir, en un manifiesto personal que se adscribe a otro, sea este otro una idea, una cosa o una misma ciudad.

La identidad se convierte en un juego delicado que, lejano de juramentos e ideas estáticas, apela netamente al propio dinamismo humano de sus emociones, nostalgias y acercamientos, acuerdos o historia misma. En esta dirección es cuando la memoria asume un rol determinante, dado que manifiesta la interpretación personal del pasado, de una realidad individual que ya no está presente, que subyace en la ausencia, en lo oculto, pero que se hace visible a través de recursos nemotécnicos como podría llegar a serlo un objeto patrimonial.

No obstante, hoy -en el caso de Chile- pocas declaratorias asumen la responsabilidad de traspasar memoria, muchas se establecen como decimonónicas que recuerdan el repudio al fenómeno de las dominaciones. Analizaremos cuatro casos -agrupados de a dos, dado su contexto de época diferente- para incursionar en esta crítica de manera concreta. Consiguientemente, se darán a conocer cuáles son los canales de declaratorias patrimoniales presentes en Chile, para entender cómo es que políticamente se engendran estos recursos del pasado.

\section{Declaratorias y canales de acción patrimonial en Chile}

Como la mayoría de los países Latinoamericanos, Chile también se adscribe a lo dictaminado en los consensos establecidos por la UNESCO. A nivel público y político, existe una figura dependiente del Ministerio de Educación, el denominado Consejo de Monumentos Nacionales (CMN). Este Consejo, previa evaluación del expediente de declaratoria presentado, es el que finalmente determina las declaratorias en las distintas categorías, a decir, Monumentos Históricos y Públicos, Zona Típica, Monumentos Arqueológicos, Santuarios de la Naturaleza.

Otro instrumento de gestión, que ha estado participando últimamente de manera activa en relación al patrimonio cultural material e inmaterial, es aquel provisto por el Consejo de la Cultura y las Artes (CNCA), que a través de fondos públicos concursables ha proporcionado creación, investigación, mecanismos de conservación e, incluso, restauración de algunos inmuebles ya 
declarados. En este instrumento, dada su naturaleza concursable, existe mayor colaboración de la sociedad civil, lo cual da cuenta de atisbos de gobernanza en tanto cooperación local del patrimonio.

Otro canal que se vincula a esta labor -por los procesos administrativos articulados para los municipios a través de los fondos- es la Subsecretaría de Desarrollo Regional y Administrativo (SUBDERE). Este mecanismo, de índole burocrática y discrecional, otorga financiamiento para programas de asistencias técnicas y provee de recursos para la gestión de iniciativas de desarrollo local, entre las que se incluyen algunas categorías de gestión y salvaguarda del patrimonio local. Esta iniciativa vincula distintos estamentos de la gestión pública a nivel ministerial y de Gobierno local, por lo que requiere un gran despliegue de recursos en la gestión de la articulación de instancias gubernamentales mencionadas.

De estos instrumentos, se desprenden las categorías de declaratoria, que son:

Monumento Histórico

Monumento Público

Zona Típica

Santuario de la Naturaleza

Monumento arqueológico

Estas categorías funcionan según sus propias descripciones y apuntan a la conservación de inmuebles o tradiciones con vocación a conservar la memoria pública.

Las declaratorias funcionan mediante mecanismos como informes y registros que documentan su valor histórico. Son revisados por el Consejo de Monumentos Nacionales, que luego dictamina su valor y categoría. Una vez que los monumentos son declarados bajo alguna de estas categorías, tanto la sociedad civil, como privados e instituciones en general, deben respetar dicha categoría conservando, por sobre todo, la fachada en los casos de inmuebles patrimoniales. Punto cuestionable, pues la fachada si bien puede entregarnos datos estilísticos y estéticos, o arrojarnos indicios de la época de su construcción, no puede entregarnos la historia completa, pues carece de contenido y su interior puede ser intervenido, porque en la ley de Monumentos Nacionales 17.288 existen vacíos importantes.

No obstante, esta ley es también utilizada como bandera de lucha social, no sólo por reconocer el pasado histórico y la identidad de localidades, sino también para frenar megaproyectos que atentan contra el paisaje urbano y la sustentabilidad del entorno, como veremos en los casos que presentaremos a continuación. 
Siguiendo con la época Colonial, momento en que se fundaron gran parte de las grandes ciudades de Chile, es fundamental comprender que la estrategia de "conquista" del territorio indígena, mal llamado "Tierra de Indios" por cronistas de época, fue paulatino. Todo lo que ocurrió desde el Siglo XVI hasta entrado el XIX fueron procesos de dominación que -dadas las difíciles circunstancias de organización social que tenían los mapuchesgatillaron las variadas estrategias de conquistas, las que a su vez tuvieron que dotarse de conocimientos específicos del territorio.

Como ya advertíamos, los mapuches tenían sus propias dinámicas sociales que funcionaron $-\mathrm{y}$ de alguna manera siguen funcionando- donde predominan las agrupaciones tribales sin un dignatario fijo. Por tanto, el acefalismo proporciona distintas dinámicas dentro del territorio. Su cosmovisión era radicalmente distinta a la espańola, lo que supuso una complejidad mayor para la milicia española que ya traía estrategias desde el Virreinato del Perú con éxito; por algo el jesuita Rosales (1877) denominó al Reino de Chile como el "Flandes Indiano".

En esta lógica, comienzan las estrategias de los fuertes de frontera (GUARDA, 1990); líneas de frontera que más bien eran móviles, y se distribuían y redistribuían según los ataques que iban padeciendo. En cada fuerte hay una historia y, en cada historia, la misma disputa. Las guerras ya no son sólo por el territorio sino por las dicotomías de las lógicas cósmicas. No podemos diseñar nuestro pensamiento sin asumir una cosmovisión, dado que emergen los valores éticos y racionales de nuestra actividad material. En muchos de los lugares donde se instalaron los fuertes se construyeron también las misiones religiosas; en esos asentamientos se establecieron luego las ciudades de la región.

Desde ya se advierte que, más que una permanente guerra de Arauco, fue un acomodo mutuo, un establecer relaciones entre habitantes locales y extranjeros (VILLALOBOS, 1987). Se asumen, entonces, transacciones económicas y una vida de frontera en base a diálogos y disputas que políticamente siguieron su curso en relación a la posterior declaración de la república de Chile, independiente de la Corona española.

\section{Caso 1: Fuerte Tucapel, comuna de Cañete}

Uno de los primeros fuertes en ser construido en el marco del desarrollo de la llamada Guerra de Arauco fue el Fuerte Tucapel, en la actual provincia de Arauco, al sur del rio Biobío, región del Biobío. El fuerte fue edificado y re-edificado varias veces y tuvo más de un emplazamiento, según lo que se investigó en las crónicas y registros y en el "Estudio de Fuerte Tucapel”, de la 
asistencia técnica de la Municipalidad de Cañete ${ }^{3}$. Data originalmente del año 1553-1554; según los estudios, se cree funcionó como tal un período de tiempo aproximado de dos meses ${ }^{4}$. Fue arrasado por los mapuches, quienes también lo quemaron, según lo descrito por Diego de Rosales 5 . En esta oportunidad, se observa en las descripciones que hubo una cruenta lucha con muertes de yaconas, mapuches y españoles (LEÓN, 1990 y VILLALOBOS, 1987)

Después de ese período, existen antecedentes que dan cuenta de un nuevo emplazamiento que evidencia su refundación en donde estuvo situado el Viejo Fuerte Tucapel, enfrentando el río del mismo nombre en la actual ciudad de Cañete. Este nuevo emplazamiento queda plasmado en la cartografía del año $1898^{6}$-la de más antigua fecha-, lo que da cuenta de la inserción de la fortificación en el ya consolidado tejido urbano de la ciudad, puesto que se ubica adyacente a hijuelas y a la plaza Pedro de Valdivia.

En el caso del Fuerte Tucapel, cabe destacar los diversos usos que albergó luego de su desmantelamiento como fortificación: el hospital militar, el Liceo A-56 (principal establecimiento educacional de la comuna) y la Casa del Deporte de la ciudad, son parte de los destinos que ha tenido el Fuerte Tucapel. Todo da cuenta de la inserción de esta área al tejido de la ciudad y de la resignificación que ha tenido como espacio público dentro de la comuna de Cañete.

El Consejo de Monumentos Nacionales declaró Monumento Nacional al Fuerte Tucapel en 1963. A pesar de esa declaratoria, hoy el fuerte yace como un mirador, sin vestigios reales de su origen. Recargado de falsos históricos, se ha convertido en un importante foco de delincuencia en el centro de la ciudad, del que los vecinos reclaman a las instituciones pidiendo alguna solución; lo que evidencia el abandono del pasado en la región.

3 Estudio realizado por los autores en el año 2015 en Cañete a través de una Asistencia Técnica de SUBDERE región del Biobío. Con material extraído del proceso del estudio, Rock y Torres realizaron una conferencia en Archive and Public Culture. University of Cape Town. Ciudad el Cabo Sudáfrica. Nov. 2016.

4 Según lo analizado por Venegas (2014) en el Estudio Histórico, Arquitectónico y Geográfico de los Monumentos Históricos: fuerte Tucapel, fuerte de Lota y fuerte de Colcura: Región Del Biobío (DIBAM), desde los siguientes textos: De Bibar, Gerónimo (1966); Marińo De Lobera, Pedro (1865); De Ercilla, Alonso(1569) De Rosales, Diego (1877); Barros Arana, Diego (1886).

5 Rosales, Diego de, Historia General del Reyno de Chile: Flandes Indiano, vol. 1, (Valparaíso, Imprenta del Mercurio, 1877). p. 486-487.

6 Cartografía Tucapel. Mapoteca Biblioteca Nacional Chile. 
En concordancia con lo expuesto anteriormente, traemos a colación el caso del fuerte de Nacimiento, fortificación española también ubicada en la región del Biobío (Fig. 1). Fue fundada en 1604 por el entonces gobernador Alonso de Ribera como parte de una política de establecimientos militares de Plazas Fuertes, ubicadas a lo largo del río Biobío para contener las asonadas indígenas, dando origen por el norte a las denominadas Plazas de la Frontera.

Al igual que otras fortificaciones de esta línea de frontera, su emplazamiento original fue absorbido por el crecimiento urbano del poblado de Nacimiento. En este sentido, cabe destacar la particularidad de que, en el año 1888, ocurra una transacción entre el gobernador de la época y el Fisco. Esta transacción involucró a la plaza de armas del pueblo, en cuyo emplazamiento se construyó una escuela de instrucción primaria y, en reemplazo de este espacio público, se utilizó el cuartel militar -ex fuerte Nacimiento-conocido como "El recinto", que a estas alturas y luego del desenlace del conflicto de frontera había perdido todo valor estratégico y militar, razón por la que fue desmantelado como fuerte. Este es el origen de la instalación de la plaza de armas de Nacimiento - principal espacio público de la ya consolidada ciudad-al interior del ex recinto militar. Cabe destacar que, a pesar de que el fuerte militar dejo de ser utilizado como tal y hoy se utiliza como plaza, fue declarado MH por el Consejo Nacional de Monumentos el 25 de marzo de 1954, bajo la tipología "inmueble infraestructura defensa".

\section{Casos de estudio postcolonial: Company Towns ${ }^{7}$}

En pleno proceso de instalación de la república, aún seguía el conflicto en el sur de Chile. Cuando se logra la independencia de la corona española, la frontera del territorio seguía siendo, hasta el río Biobío, la histórica frontera sur de la colonia. Con la instalación de la república esta frontera se mantuvo, dado que hacia el sur seguía sin ser "conquistado"; la denominada "tierra de indios" indicaba que la soberanía y el poder indígena mapuche seguían estando latentes.

Tras una invasiva y devastadora estrategia de reducciones indígenas y exterminio bajo el mandato del coronel Cornelio Saavedra, se adscribe el territorio indígena a la república unificando así el sur hacia el año 1883 (NAVARRO, 1909). No obstante, ya en 1851, al otro lado del río Biobío, se instala la primera industria de Chile. Una industria extractiva de carbón de piedra que adoptará los cánones de Company Town inglés.

7 Denominamos Company Town a los asentamientos urbanos que se edificaron para contener las instalaciones y habitaciones de mano de obra y profesionales de industrias. Estas son las primeras "ciudades" de la frontera. 


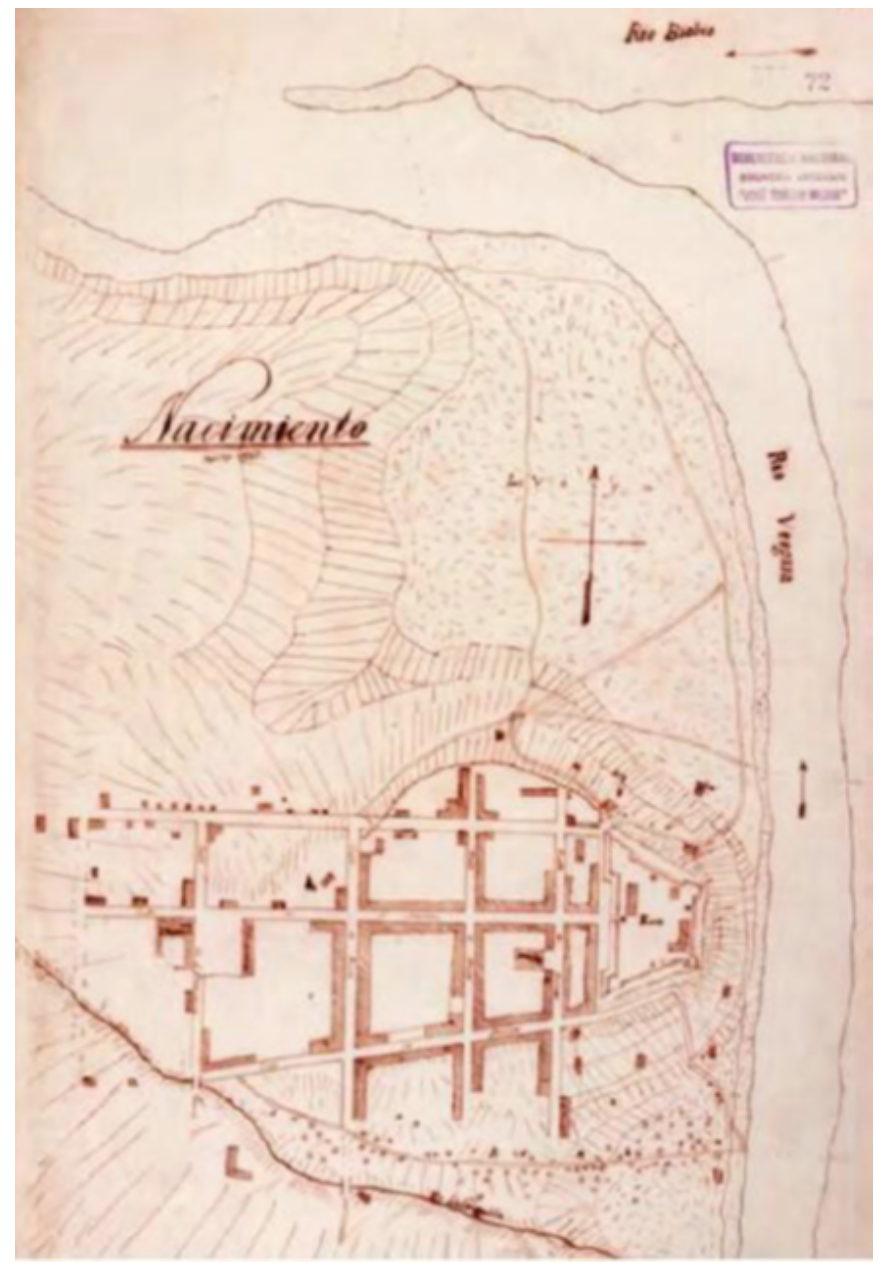

Figura 1. Plano de Nacimiento en 1855.

Fuente: Portal web Memoria Chilena

Un visionario español llamado Matías Cousiño invirtió tiempo, dinero y capital humano en Lota para explotar esta piedra, que para entonces era "preciosa", después del surgimiento de la tecnología a vapor: la llamaban "oro negro". No había barco que no parase en las costas del continente para recargar combustible, ya que los barcos que venían del viejo continente y de África pasaban por el estrecho de Magallanes. Se construyeron vías férreas y rutas marinas; todo parecía transportarse a carbón. Esto decae con la apertura del canal de Sombrero y, luego, con la llegada del petróleo: dos elementos clave de la disolución de la industria. 
En 1997 se cierran las minas, al cabo de casi doscientos años de historia. Cada rincón de este pueblo podría hablar por sí mismo. Sus calles son archivos y registros no sólo de historia, sino de apropiación e identidad. En sus calles se respira memoria, y se convierten en archivos y personas ya domesticadas. En Lota se han reconocido Monumentos Históricos desde 1926. Hoy tiene un total de diez Monumentos Históricos declarados por el CNM y en 2014 fue declarado Zona Típica (ZT).

\section{El caso de Tomé}

Como Lota, la ciudad de Tomé también forma parte del área metropolitana de Concepción, en la región del Biobío, ubicada en el borde costero a $32 \mathrm{~km}$ de distancia de la capital regional, Concepción. Su fundación no está del todo definida, pero se data en el año 1544.

El origen urbano de Tomé está directamente ligado a su emplazamiento como articulador de territorios rurales adyacentes; el asentamiento de pescadores que dio origen a que, en el año 1760, recibiera la denominación de caleta y, a partir de esta y en vínculo con el desarrollo de la actividad productiva molinera e industrial, fuese declarada en 1858, por el Congreso Nacional Puerto Mayor, de interés para el comercio nacional e internacional y para el desarrollo de diversas actividades industriales, dentro de las cuales la de mayor significación y desarrollo fue la industria textil.

Tanto el origen como el desarrollo urbano de Tomé se encuentran directamente asociados a su condición de puerto. En un primer período, de 1842 a 1876, el puerto estuvo ligado a la salida del trigo proveniente de las áreas rurales que la circundaban, por lo que se llegó a exportar desde allí el 90,95\% de la producción nacional. Esta actividad de intercambio estuvo sustentada materialmente por la edificación de una serie de molinos que vinieron a consolidar un paisaje urbano marcado por hitos arquitectónicos de índole industrial. De manera complementaria, se fue desarrollando la red vial y ferroviaria de la comuna, vinculada a las redes de Lota y fuentes carboníferas, que sustentaban la tecnología a vapor de los mismos barcos que paraban en el puerto de Tomé.

En este contexto, existió un segundo periodo de desarrollo económico de la comuna, que estuvo marcado por dos hitos: la instalación de nuevas bodegas vitivinícolas frente al muelle fiscal; y la fundación en 1865 de la fábrica de Pańos Bellavista en los antiguos edificios del molino caracol. Este último acontecimiento vendrá a consolidar el desarrollo urbano de la comuna, dada la edificación de grandes complejos industriales y, consecuentemente, dará pie a la época de oro de la industria textil en Tomé. En 1885 el gobierno concede el título de ciudad a la villa de Tomé, asumiéndola como cabecera del Departamento de Coelemu: nacía otro "Company town" en el territorio. 
Por último, cabe destacar que en 1932 Tomé es conocido como el primer puerto textil de Chile, dado que, junto a la ya mencionada instalación de la industria Bellavista, se instalan otras fábricas: Tejidos El Morro, Empresa de Tejidos Punto de Fantasía e Italoamericana. Esta última cierra en 1979, lo que marcó el declive de la actividad productiva textil en Tomé. En este contexto y dada la necesidad de generar estrategias para la subsistencia de la fábrica, Bellavista se fusiona con Pańos Oveja surgiendo la empresa Bellavista Oveja Tomé. El cierre definitivo de la empresa se realiza en 2007. A partir de ese momento, se consolida un sentir en torno al valor patrimonial de la empresa Bellavista, sentir que se manifiesta en múltiples instancias de organización ciudadana. La de mayor visibilidad en torno a la problemática del patrimonio tomecino es la Mesa Ciudadana por el Patrimonio de Tomé, cuya labor de congregación de diversas agrupaciones de la sociedad civil en torno a la gestión del patrimonio permitieron que en 2017 el Consejo de Monumentos Nacionales declarara Monumento Histórico a la totalidad de las antiguas dependencias de la fábrica Bellavista. Una victoria de la lucha en contra los megaproyectos de urbanización que instalan las inmobiliarias en la región.

\section{Análisis general}

Dada la constitución historia de los dos períodos de tiempo y los cuatro casos de estudio, vamos a establecer un análisis de cada caso para luego incursionar en una conclusión, o bien en preguntas abiertas para su discusión futura.

Casos de fuertes en período colonial

En términos generales se puede decir que la ciudad colonial del sur de Chile fue dándose de manera paulatina y casi espontánea después del asentamiento de los fuertes españoles y las misiones, primero jesuitas y luego franciscanas. Lo que, además de cambiar el paisaje de pequeños caseríos distantes los unos de los otros -como solían construir las rukas mapuches-, vino a configurar el urbanismo desde dos hitos: reconocimiento del habitar de la milicia y la religión católica. Ambos con fines y propósitos claros: conquistar territorio, mano de obra, formas de pensar, costumbres y cosmovisiones según los lineamientos de la corona española. En adelante, dicha configuración permearía la organización urbana en damero español, que se inició en la plaza de armas, en cuyo entorno estaría la catedral y los edificios gubernamentales.

El caso del fuerte Tucapel, que hoy yace dotado de falsos históricos intervenciones arquitectónicas tendientes a restituir su autenticidad formal-, tiene además una construcción utilizada como liceo municipal próxima a 
ser desocupada sin proyecto que revitalice su uso, además de una especie de parque-mirador, lo que refleja la confusión del pasado y del simbolismo cultural del fuerte como construcción colonial. Se emplaza en Cañete, provincia de Arauco, actual zona de conflicto. Curiosamente, este fuerte español está próximo a una de las victorias mapuches más grandes: la muerte de Pedro de Valdivia, el gran conquistador. No hay ningún atisbo siquiera de lo que había en este sitio; hoy sigue abandonado, como su historia. No obstante, al estar emplazado próximo al centro urbano y comercial de la ciudad, hace reflexionar sobre su vocación pública. En esta dirección es que consideramos que las declaratorias de monumentos históricos, independientemente de cuál sea su origen, pueda ser reconocida desde la identidad del lugar, con el fin de promover espacios públicos históricos desde una sustentabilidad.

A diferencia del caso del fuerte de Tucapel, el fuerte de Nacimiento, por estar resignificado como plaza pública, manifiesta y expresa un significado similar al del fuerte original: habitar el espacio interno del fuerte. En el siglo XVII fue habitado por la milicia y familias espańolas. Hoy, al convertirse en plaza, también es habitado por ciudadanos que ahora moran en él, no con objetivos militares sino con objetivos de recreación, recordando su origen constructivo como fuerte. Las intervenciones arquitectónicas que se le han hecho han sido de diversa índole, destacando la última intervenciónrestauración parcial del fuerte de Nacimiento -luego del terremoto del año 2010 - como un proyecto apreciable en términos históricos y de rescate de memoria en su complejidad.

En dicha restauración sale a la luz la materialidad de ladrillo, que subsistió como memoria a diferencia de la madera del fuerte Tucapel, que se esfumó en cada saqueo y quema. ¿Será entonces que la materialidad evidencia la memoria? ¿Construimos pensando en la posteridad? Sin duda, uno de los archivos que la ciudad posibilita, además de la observación de dinámicas sociales, es la categorización de la memoria en función a la materialidad y estilos utilizados. En el caso del ladrillo de Nacimiento, la última intervención del arquitecto rescata de manera fina el quehacer de los artesanos, solicitando construir ladrillos para el fuerte a la usanza, elemento clave en la sustentabilidad de dicho monumento, pues con dicho acto activó de inmediato la red de memoria, artesanos y pasado de la población, reivindicando la identidad del $\mathrm{MH}$.

\section{Casos de Company towns en época postcolonial}

No podemos desconocer el llamado colonizante, dominante y complejo que provocó la industrialización en el sur de Chile. Reconfigura el paisaje ecológico, lo explota y, sobre todo, resignifica el habitar de quienes vienen 
migrando desde el campo para trabajar en un nuevo rubro. En este sentido, la memoria se configura bajo un propósito de especificidad o profesionalización de esta mano de obra y de imposición de dinámicas dentro del territorio, dispuestas por la configuración del desarrollo.

En el caso de Lota, ciudad puerto, como también lo fue Tomé, el motor de desarrollo fue la extracción del carbón de piedra, materia prima para todo el desarrollo de la tecnología a vapor. Por otro lado, la vocación agrícola y textilera de Tomé instauró una ciudad cuya proximidad al mundo rural generó grandes contrastes, más aun cuando intencionadamente se vuelve al rubro textil.

El ser humano va adaptándose a estas nuevas formas y maneras de habitar, de construir la ciudad y la sociedad. Jerarquizaciones, saberes y tecnología son sólo algunos de los elementos que comienzan a operar de manera rápida en las primeras ciudades "modernas" del sur. Con el paso del tiempo, al cabo de generaciones que se desenvolvieron, tecnificaron y aprendieron de las técnicas y la propia evolución de ellas, es que comienza a aparecer la identidad. Una identidad que, si bien fue adquirida, por mantenerse presente en distintas generaciones va a permear la fibra emocional cultural. Se "apropiaron" dinámicas impuestas y se autonomizaron, provocando el efecto de real identidad, apelando a la nostalgia de sentirse parte de un algo. Sin embargo, con las políticas neoliberales y capitalistas terminaron por borrarse, con lo que quedaron así grandes fábricas y espacios urbanos en abandono.

El capitalismo no ha cesado y hoy estos pueblos son objetivos para megaproyectos: un blanco perfecto donde las altas tasas de cesantía terminan por bajar el valor del suelo y, por tanto, se vuelven atractivos para cualquier proyecto de "desarrollo" (sean casas, edificios, malls, etc.), como en el caso de Tomé sobre todo, que es el más reciente. Pero fue declarado zona típica en 2014, observando con ello como los procesos de patrimonialización también se vuelven banderas de lucha social por mantener vivos los paisajes urbanos que sustentan la memoria y, a partir de ahí, la identidad de diversas localidades.

Desde la colonia a la república, cada quien con sus recursos dominó el territorio para crear lugares sin espacios, entendiendo "lugares" como aquello edificado e intervenido por el hombre, y el espacio como lo dado por la naturaleza (HEIDEGGER, 1956). En este sentido, la ciudad es testigo de procesos sociales, pero también forma parte de un sinfín de simbolismos que operan de manera relativamente simultánea en un mismo grupo humano. Muchos de ellos guardan relación con la gobernanza de la memoria, otros con el disciplinamiento de los cuerpos. Y, de esta manera, ¿cómo es que sugerimos patrimonializar espacios?

Pareciera que sacralizar lugares del pasado dentro de la ciudad se vuelve objetivo de procesos de reconocimiento y auto-reconocimiento social, o bien 
-y en paralelo- de dominaciones del pasado histórico en un afán de imponer identidad. ¿Cuán importante, o bien cuánto abordamos la sustentabilidad desde la identidad? La discusión queda abierta.

\section{Referencias}

ARFUCH, Leonor. Identidades, Sujetos y subjetividades. Buenos Aires: Prometeo Editores, 2002.

BARTHES, Roland. El susurro del lenguaje, Más allá de la palabra y de la escritura. México: Ediciones Paidós, 1984.

BOURDIEU, Pierre. Leçon sur la leçon. París: Editions de Minuit, 1982.

CONSEJO de Monumentos Nacionales. Estudio Histórico, Arquitectónico y Geográfico de los Monumentos Históricos. Fuerte de Tucapel, Fuerte de Lota y fuerte de Colcura: Región Del Biobio. Etapa 4 Informe Final. Consultora Estudiocero Arquitectura y Patrimonio. (Acervo: DIBAM Chile.)

CHIHUAILAF, Elicura. Recado confidencial a los chilenos. Santiago: LOM, 1999.

DERRIDA, Jacques. Firma, acontecimiento, contexto. Madrid: Cátedra, 1971.

FOUCAULT, Michel. La arqueología del saber. Buenos Aires: Siglo XXI Editores, $1969[2005]$.

FOUCAULT, Michel. Vigilar y Castigar. Buenos Aires: Siglo Veintiuno Editores, 1975[2009].

FREUD, Sigmund. El mal estar de la cultura. Biblioteca Libre Omegalfa, 2010 [1929].

GEERTZ, Clifford. La Interpretación de las Culturas. España: Gedisa Editorial, 1973[2006].

GEERTZ, Clifford. Conocimiento Local. Barcelona: Paidós, 1983 [1994].

GUARDA, Gabriel. La ciudad Chilena del siglo XVIII. Buenos Aires: Centro Editor de América Latina, 1968.

GUARDA, Gabriel. Flandes Indiano. Las fortificaciones del Reino de Chile, 1541-1826. Santiago: Ediciones Universidad Católica de Chile, 1990.

HALL, Stuart. Who needs “identity"? In: Hall, S. D. Questions of cultural identity. Londres: Sage, 2002 [1996], p. 15-30.

HEIDEGGER, Martín. Construir, habitar, pensar. Madrid: Oficina de artes y ediciones, 2015 [1956]. 
LEÓN, Leonardo. Maloqueros y conchavadores en Araucanía y las Pampas, 1700-1800. Temuco: Ediciones Universidad de la Frontera, 1990. (Serie Quinto Centenario)

NAVARRO, Leonardo. Crónica Militar de la conquista y pacificación de la Araucanía desde el año 1859 hasta su complete incorporación al territorio nacional. Chile: Pehuén, 2004 [1909].

ROCK, María Esperanza. Voces de Lota. Relatos de la ciudad del carbón. Santiago: Editorial Universitaria, 2018.

ROSALES, Diego de, Historia General del Reyno de Chile: Flandes Indiano. Valparaíso: Imprenta del Mercurio, 1877, v. 1.

STEWART, Daniel \& ROCK, María Esperanza. Respuestas locales a la política global del Imperio español: tenencia de tierras indígenas en Chile, siglo XVII. Historia Critica, n. 69, 2018, p. 115-135. doi: 10.7440/histcrit69.2018.07

TODOROV, Tzvetan. La conquista de América. El problema del otro. Buenos Aires: Siglo XXI Ediciones, 2002[1982].

TORRES, A. \& ROCK, M. E. Dimensiones culturales y territoriales de las edificaciones campesinas del valle central de Chile. In: ALARCÓN, J. A propósito de los gallineros y otras construcciones, en el valle central de Chile. Santiago: Diseño Editorial, 2018.

TRIVIÑOS, Gilberto. La Polilla de la Guerra en el Reino de Chile. Santiago: Ed. Noria, 1994.

VILLALOBOS, Sergio. Breve historia de Chile. Santiago: Editorial Universitaria, 1987. 
María Esperanza Rock Núñez. Profesora de la Universidad San Sebastián, Sede Tres Pascualas (Chile). Teórica e Historiadora del Arte y Doctora en Etnohistoria, por la Universidad de Chile. Lidera la Red de Académicos del Sur y forma parte de la iniciativa de investigación Archive and Public Culture, Universidad de Ciudad del Cabo (Sudáfrica). Recientemente publicó el libro Voces de Lota. Relatos de la Ciudad del Carbón (Santiago: Editorial Universitaria, 2018).

E-mail: esperanzarock@u.uchile.cl

Andrés Torres González. Profesor de la Universidad San Sebastián, Sede Tres Pascualas (Chile). Arquitecto por la Universidad de Artes y Ciencias Sociales ARCIS, Magister en Geografía con mención en Organización Urbana Regional por la Universidad de Chile, Magister en Pedagogía Teatral por la Universidad del Desarrollo. Estudios de preservación histórica en el Centro Nacional de Conservación, Restauración y Museología CENCREM La Habana-Cuba. Cursa estudios de doctorado en el programa Territorio, Espacio y Sociedad de la Facultad de Arquitectura y Urbanismo de la Universidad de Chile.

E-mail: atorresg@ug.uchile.cl 